Article

\title{
Precipitation Hardening on Mechanical and Corrosion Properties of Extruded Mg10Gd Modified with Nd and La
}

\author{
Petra Maier ${ }^{1, *}$ (D), Maximilian Bechly ${ }^{1}$, Chamini L. Mendis ${ }^{2}$ and Norbert Hort ${ }^{3}$ \\ 1 School of Mechanical Engineering, University of Applied Sciences Stralsund, 18435 Stralsund, Germany; \\ maximilian.bechly@fh-stralsund.de \\ 2 Brunel Centre for Advanced Solidification Technology, Brunel University London, London, UB8 3PH \\ Uxbridge, UK; chamini.mendis@brunel.ac.uk \\ 3 Helmholtz-Zentrum Geesthacht, Magnesium Innovation Center, 21502 Geesthacht, Germany; \\ norbert.hort@hzg.de \\ * Correspondence: petra.maier@hochschule-stralsund.de; Tel.: +49-3831-456914
}

Received: 13 July 2018; Accepted: 3 August 2018; Published: 14 August 2018

\begin{abstract}
To improve the mechanical and corrosion properties of $\mathrm{Mg} 10 \mathrm{Gd}, \mathrm{Nd}$ and La are added, and from that, the influence of precipitation hardening was studied. An increase in strength, by decreasing grain size and increasing the volume fraction of Rare Earth-rich precipitates, has been found when increasing the amount of alloying elements. Alloys containing La appear less ductile. Where crack propagation is studied using 3-point bending on Mg10Gd and Mg10Gd1Nd, the failure is mostly driven by twinning; the alloys with La show suppressed twinning, but crack initiation and propagation is caused by brittle and coarse precipitates. Precipitation hardening did not improve fracture toughness and was mostly based on strong grain growth and low solubility of $\mathrm{La}$ in $\mathrm{Mg}$. With added alloying elements, the grain size was found to be slightly smaller in the T6 condition-precipitates seem to pin grain boundaries and therefore limit grain boundary mobility. Alloys containing $\mathrm{Nd}$ showed the best precipitation hardening response. Corrosion behavior, investigated by voltammetry and immersion, showed the best behavior in the precipitation-hardened condition. Corrosion rates and surface morphology are used to discuss corrosion properties.
\end{abstract}

Keywords: Mg-RE alloys; fracture toughness; voltammetry; immersion; corrosion morphology

\section{Introduction}

Rare Earth (RE) elements are useful in Mg alloys when a high strength, creep resistance, and moderate corrosion rate is required [1]. The best corrosion resistance and strength combination among binary Mg-Gd alloys has been found in Mg10Gd [2]. Here it is used as the reference material, and is often alloyed with $\mathrm{Nd}, \mathrm{Y}$, and $\mathrm{Zr}$ to increase creep, fatigue, and corrosion properties. A review by Mirza et al. [3] on Mg-RE alloys, on the basis of a higher Gd content for fatigue studies, presented promising results: Effectively weakened crystallographic textures; suppressed twinning; and enhanced fatigue strength. The role of $\mathrm{Nd}$ and/or $\mathrm{La}$ in $\mathrm{Mg} 10 \mathrm{Gd}$, in the mechanical properties and corrosion behavior during precipitation hardening, is of interest in this study, especially its influence on crack propagation. Research on 3-point bending of as-cast Mg10Gd alloys, with and without $\mathrm{Nd}$, where the microstructure reveals very coarse grain sizes (up to $1000 \mu \mathrm{m}$ ), shows a strong crack reorientation (zigzag) by twins as a result of plastic deformation; twin boundaries seem to "carry" the crack from grain to grain [4]. Previous work, Reference [5], has shown a low fracture toughness of the as-extruded Mg10Gd material, mostly by alloying with La, which is due to brittle and coarser precipitates. 
The high hardness of secondary phases in Mg-RE and Mg-Al, most likely accompanied with low ductility, is shown in Reference [6,7], where nano-indentation analysis was used to determine the hardness of individual particles. The hardness of the secondary phases is three times higher than that of the alpha phase. According to Rokhlin [1], the Mg-La system forms coarse and brittle crystals that decrease the overall elongation of the alloy. Ternary solubilities and solidification details of the Mg-Nd-La system were examined in Reference [8]. Mg-Gd belongs to the high solubility alloying systems-a solubility up to $23.5 \mathrm{wt} . \%$ at $550{ }^{\circ} \mathrm{C}$ is reported [9]. $\mathrm{Mg}-\mathrm{Nd}$ and $\mathrm{Mg}$-La phase diagrams show a low solubility of the alloying element; $2.2 \mathrm{wt} . \%$ at $500{ }^{\circ} \mathrm{C}$ is reported in Reference [10] for $\mathrm{Mg}-\mathrm{Nd}$ and $0.06 \mathrm{wt} . \%$ for $\mathrm{Mg}$-La, respectively. When $\mathrm{Mg}$ alloys are designed as biodegradable implant materials, a good combination of mechanical and corrosion properties is expected. To avoid pitting corrosion, a uniform corrosion layer is wanted. From the RE in this investigation, Gd is one of the elements with high solubility in $\mathrm{Mg}$. As a result of this, the passivation behavior in $\mathrm{Cl}$-ion containing solutions seem to be improved. Corrosion in modified Mg10Gd alloys is mainly influenced by the micro-galvanic corrosion between the $\mathrm{Mg}$ matrix and intermetallic phases, which are nobler than the matrix. However, Gd enriched zones reduce the galvanic corrosion between $\mathrm{Mg}_{5} \mathrm{Gd}$ phases and the $\mathrm{Mg}$ matrix. [11]. Mg10Gd1Nd is of interest due to its good cell adhesion behavior by pre-incubation under cell culture conditions [12]. It could be shown that $6 \mathrm{~h}$ pre-incubation is enough to form a natural protective layer suitable for cell culture. La has been considered as a substitute for the precious rare earth element $\mathrm{Nd}$ [13]. La containing alloys show a protective layer containing $\mathrm{Mg}(\mathrm{OH})_{2}$ and $\mathrm{La}$ oxide, which enhances the corrosion resistance [14].

This study focuses on microstructural changes, such as grain size and presence, and the size of RE-rich precipitates during heat treatment and its influence on mechanical and corrosion properties. The influence of microstructure features, such as twinning or a large secondary phase, on its toughness (crack initiation and propagation) is of interest.

\section{Materials and Methods}

The Mg10GdxNdxLa ( $x=0$ and/or $1 \mathrm{wt} . \% \mathrm{Nd}, \mathrm{La}$ ) alloys were cast at the HZG using permanent mold direct chill casting. $\mathrm{Gd}, \mathrm{Nd}$, and La were added in terms of pure elements to the Mg melt before casting. The cast alloys were then annealed and extruded at a temperature of $420{ }^{\circ} \mathrm{C}$, at a speed of $2.2 \mathrm{~m} / \mathrm{min}$, and an extrusion ratio of $37: 1$. Solution heat treatment (T4) was done at $525^{\circ} \mathrm{C}$ for $24 \mathrm{~h}$; precipitation hardening (T6) at $250{ }^{\circ} \mathrm{C}$ in $2 \mathrm{~h}$ intervals up to over-aging at $16 \mathrm{~h}$. Tensile properties were measured at room temperature with an initial strain rate of $1 \times 10^{-3} \mathrm{~mm} \mathrm{~s}^{-1}$. Samples, 5 to 10 , were tested for each alloy. Vickers hardness (HV1) was used to determine changes during heat treatment with approximately 30 indents each, under a load of $1 \mathrm{~kg}(9.807 \mathrm{~N})$, and the average values are reported. 3-point bending was conducted using a span of $40 \mathrm{~mm}$ on $70 \times 10 \times 8 \mathrm{~mm}^{3}$ samples at a speed of $1 \mathrm{~mm} / \mathrm{min}$ (plates were tested in the upright position to guarantee longer crack propagation). Micrographs revealed the microstructure, and with this, the influence of twins and larger precipitates on crack propagation was determined. The grain size was measured by the linear intercept method. Bending tests were also done to 8,10 , and $12 \%$ outer strain only, to check deformation before crack initiation. SEM imaging was used to discuss the fracture surface and SEM-EDX to determine the intermetallic phases. The overall chemical composition was analyzed with inductively coupled plasma-optical emission spectroscopy (ICPOES).

Due to the possible application of Mg10Gd1Nd as a biodegradable material, corrosion tests were done in Ringer solution. The corrosion rate (CR) is based on weight loss from immersion tests, which were performed using 3 samples each. The cylindrical samples had an initial diameter of $10 \mathrm{~mm}$ and a height of $7 \mathrm{~mm}$ and they were exposed to $500 \mathrm{~mL}$ at $37^{\circ} \mathrm{C}$ for 7 days. The solution was changed after 4 days to avoid an increase in the $\mathrm{pH}$ value. The weight loss was measured by removing the corrosion products with chromic acid.

The potentiodynamic measurements were conducted on samples immediately after grinding with 600,1200 , and 2400-mesh paper, and cleaning in an ultrasonic bath in ethanol. A 3-electrode flow 
cell, using a counter electrode, an Argenthal reference electrode, and a working electrode (sample) with a measurement area of $\sim 95 \mathrm{~mm}^{2}$ (diameter of $\sim 11 \mathrm{~mm}$ ) all in a 170-mL glass chamber, was used to evaluate polarization (current density-potential) curves. To mimic the human body temperature, the Ringer solution was heated to $37^{\circ} \mathrm{C}$. To keep the $\mathrm{pH}$ value low ( 8.5; initial pH value 6.5$)$, the electrolyte was circulating using a pump (IKA ICC basic, IKA-Werke GmbH \& Co. KG, Staufen, Germany). To result in an anodic corrosion, the curve was traced with a scan rate of $50 \mathrm{mV} / \mathrm{min}$ from a negative potential of $-2000 \mathrm{mV}$ to a positive potential of $500 \mathrm{mV}$.

The corrosion rate taken from the immersion tests was compared with corroded areas from polarization out of cross-sectional micrographs, see also Reference $[15,16]$ for further experimental descriptions. The pitting factor (deepest pit divided by the average penetration) as well as the amount and size of the pits are used to describe the corrosion morphology.

\section{Results and Discussion}

\subsection{Initial Mechanical Properties and the Influence of Heat Treatments on Microstructure}

The addition of $\mathrm{Nd}$ and La generally improves the yield strength in tension (TYS) and compression (CYS), but reduces the ductility (elongation and compressive strain CS) compared with the binary Mg-Gd alloy, see Table 1 (the data is taken from Reference [5]). The ultimate strength in tension (UTS) and compression (UCS) does not change significantly in the ternary and quaternary alloys, resulting in an increase in a yield to tensile stress ratio, in short, a yield-tensile ratio. Mg10Gd has a yield-tensile ratio of 0.53 , which increases for the quaternary alloy system $\mathrm{Mg} 10 \mathrm{Gd} 1 \mathrm{Nd} 1 \mathrm{La}$ to a ratio of 0.65 . The same trend is seen under compression; Mg10Gd has a yield-compressive ratio of 0.33 , and the quaternary alloy system Mg10Gd1Nd1La of 0.41 . There is no significant tension-compression yield asymmetry, but because of the preferred loading conditions, there is a much higher UCS.

Table 1. Tensile and compressive properties and hardness properties of extruded alloys [5].

\begin{tabular}{cccccccc}
\hline Alloy & TYS (MPa) & UTS (MPa) & Elongation (\%) & CYS (MPa) & UCS (MPa) & CS (\%) & HV1 \\
\hline Mg10Gd & $131.4 \pm 2.2$ & $248.9 \pm 2.7$ & $22.9 \pm 2.8$ & $133.7 \pm 0.4$ & $399.2 \pm 10.2$ & $26.1 \pm 1.3$ & $66.8 \pm 3.5$ \\
Mg10Gd1Nd & $138.2 \pm 3.3$ & $256.0 \pm 4.1$ & $17.3 \pm 1.2$ & $148.9 \pm 5.7$ & $397.5 \pm 14.2$ & $16.8 \pm 1.2$ & $70.6 \pm 6.3$ \\
Mg10Gd1La & $149.2 \pm 8.4$ & $248.0 \pm 3.9$ & $17.0 \pm 3.7$ & $149.4 \pm 1.1$ & $395.8 \pm 12.5$ & $18.4 \pm 0.5$ & $75.0 \pm 4.6$ \\
Mg10Gd1Nd1La & $165.4 \pm 0.9$ & $253.4 \pm 2.2$ & $12.2 \pm 1.1$ & $161.2 \pm 1.3$ & $393.4 \pm 23.3$ & $13.0 \pm 2.1$ & $77.4 \pm 4.9$ \\
\hline
\end{tabular}

The micro-hardness (HV1) of samples increases with increasing amounts of alloying elements. $\mathrm{La}$, compared to $\mathrm{Nd}$, shows a more pronounced effect on hardness. Due to the low solubility of $\mathrm{La}$ in $\mathrm{Mg}$, the volume fraction of secondary phases is higher than in $\mathrm{Mg}-\mathrm{Nd}$. As a result of the complex lattice structure of secondary phases, the hardness is higher, which unfortunately results in a higher brittleness.

A rather small grain size $(<24 \mu \mathrm{m})$, developed by dynamic recrystallization during extrusion, is described in Reference [5]. Adding Nd and/or La (see Table 2) decreases the average grain size down to $13 \mu \mathrm{m}$ and increases the volume fraction of secondary phases, mainly $\mathrm{Mg}_{5}(\mathrm{Gd}, x)$, where $x=0$, and/or $1 \mathrm{wt} . \% \mathrm{Nd}$, and/or La, which are dispersed in the extrusion direction, see the horizontal alignment in Figure 1. The secondary phases in the alloys containing La reaches a size of several $\mu \mathrm{m}$.

Table 2. Chemical composition in wt. $\%$, grain sizes in $\mu \mathrm{m}$, and secondary phases in extruded alloys investigated [5].

\begin{tabular}{cccccc}
\hline Alloy & Gd & Nd & La & Grain Size & Secondary Phases \\
\hline Mg10Gd & 9.7 & - & - & $23.9 \pm 11.8$ & $\mathrm{Mg}_{5} \mathrm{Gd}$ \\
Mg10Gd1Nd & 9.8 & 0.88 & - & $16.8 \pm 8.3$ & $\mathrm{Mg}_{5}(\mathrm{Gd}, \mathrm{Nd})$ \\
Mg10Gd1La & 9.7 & - & 0.83 & $14.7 \pm 6.5$ & $\mathrm{Mg}_{5}(\mathrm{Gd}, \mathrm{La})$ \\
Mg10Gd1Nd1La & 9.5 & 0.88 & 0.89 & $13.2 \pm 5.6$ & $\mathrm{Mg}_{5}(\mathrm{Gd}, \mathrm{Nd}, \mathrm{La})$ \\
\hline
\end{tabular}




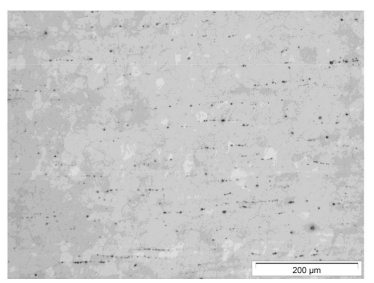

(a)

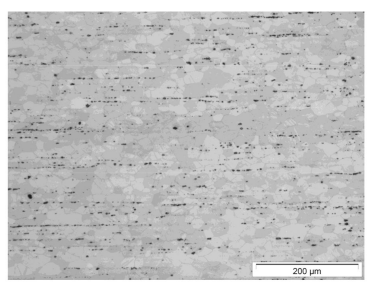

(b)

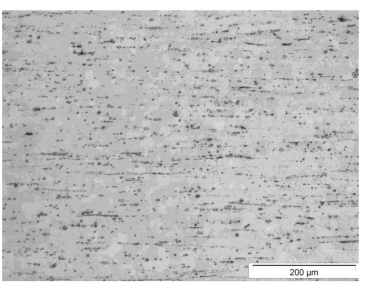

(c)

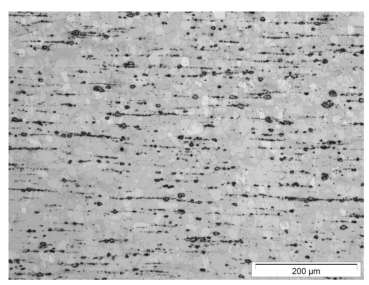

(d)

Figure 1. Microstructure of extruded alloys: (a) Mg10Gd; (b) Mg10Gd1Nd; (c) Mg10Gd1La; and (d) Mg10Gd1Nd1La.

During solution heat treatment (T4), most secondary phases are dissolved in Mg10Gd and Mg10Gd1Nd (apart from some cuboid shaped phases of $\mathrm{GdH}_{2}$ ). The alloys containing La still show remaining secondary phases of globular shape and uniform distribution. The low solubility of the alloying element $\mathrm{Nd}$, and especially of the alloying element La, explains the remaining secondary phases, even after solution heat treatment of $24 \mathrm{~h}$.

T4 increases the grain size significantly, especially for the binary Mg10Gd alloy, where the grains grow from $24 \mu \mathrm{m}$ to $140 \mu \mathrm{m}$ (see Figure 2). Alloying $\mathrm{Nd}$ and La hinders grain growth, the secondary phases reduce the grain boundary mobility, and the grain size only increases up to $90 \mu \mathrm{m}$. Alloying with $\mathrm{Nd}$ rather than alloying with La acts slightly more positively to restricting grain growth-during T4, the grains in Mg10Gd1Nd grow to $106 \mu \mathrm{m}$, and in Mg10Gd1La, up to $119 \mu \mathrm{m}$.

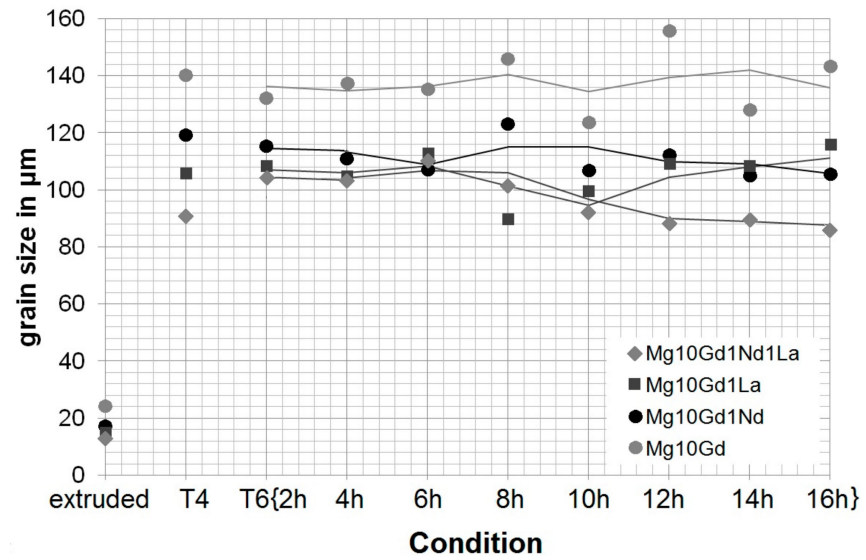

Figure 2. Effect of adding $\mathrm{Nd}$ or/and La on grain size development during precipitation hardening.

During precipitation hardening (T6) over $16 \mathrm{~h}$, the grain size does not change greatly, compared to the solution heat-treated condition (Figure 2). Either the thermal activity is low enough or the precipitates seem to pin grain boundaries, and therefore limits grain boundary mobility. Only in the binary system Mg10Gd do the larger grains grow, see the micrographs in Figure 3 and the grain size distribution in the histograms in Figure 4. Figure 4a shows a shift of counts (number of grains) towards larger grains (grey bars compared to black bars); small grains (up to $20 \mu \mathrm{m}$ ) disappear, and medium and larger grains grow, even occasionally up to a few hundred $\mu \mathrm{m}$. Such large grains are not found in the higher alloyed systems (Figure $4 b-d$ ). 


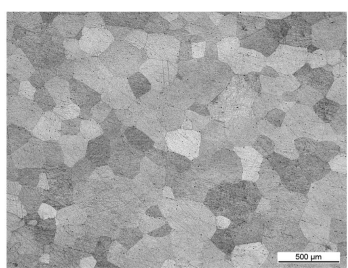

(a)

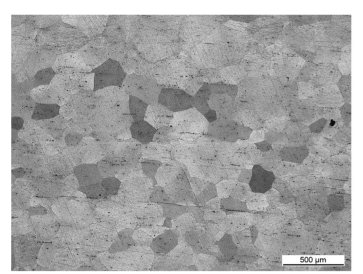

(b)

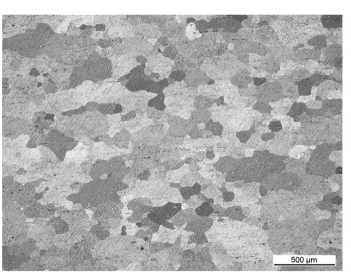

(c)

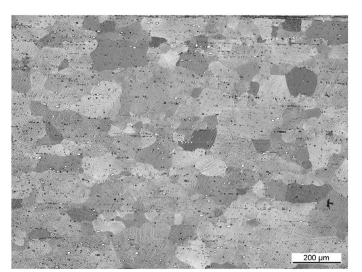

(d)

Figure 3. Microstructure of precipitation hardened alloys: (a) Mg10Gd; (b) Mg10Gd1Nd; (c) Mg10Gd1La; and (d) Mg10Gd1Nd1La.

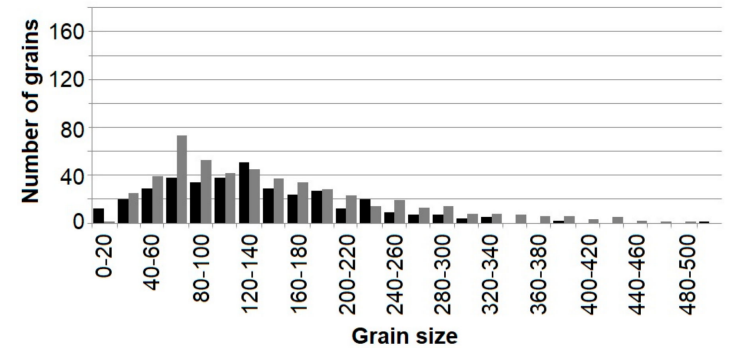

(a)

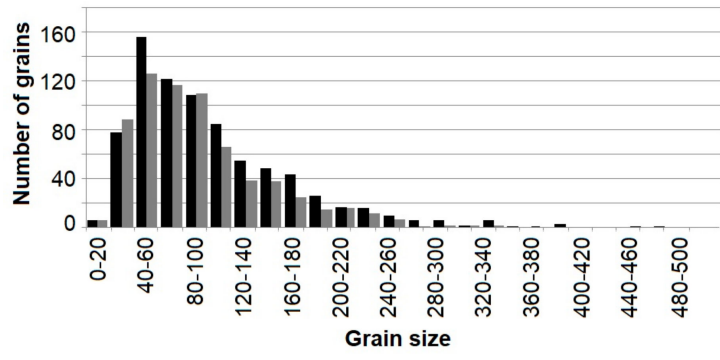

(c)

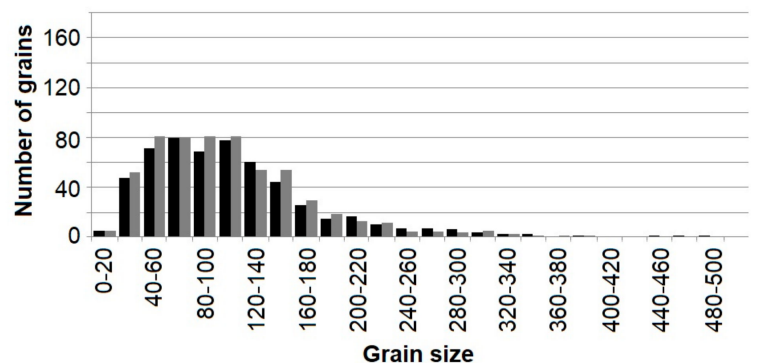

(b)

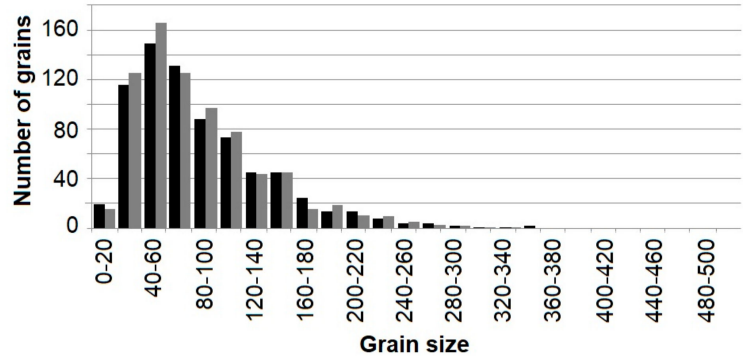

(d)

Figure 4. Microstructure of precipitation hardened alloys: (a) Mg10Gd; (b) Mg10Gd1Nd; (c) Mg10Gd1La; and (d) Mg10Gd1Nd1La (black bars: T4 and grey bars: T6-12 h).

\subsection{Heat Treatment on Mechanical Properties: Hardness and Bending Strength}

Solution heat treatment (T4) reduces the hardness of all four alloys (Figure 5). The greatest decrease is found for the binary system $\mathrm{Mg} 10 \mathrm{Gd}$, where the grain growth is the most pronounced and all the secondary phases are dissolved in solid solution. The quaternary alloy Mg10Gd1Nd1La retains the highest hardness. Here, the secondary phases, which are not dissolvable, are affecting the hardness, as well as hindering the grain size and mobility during heat treatment.

The age-hardening response (T6) is the lowest for Mg10Gd (Figure 5), where, after $12 \mathrm{~h}$, the greatest hardness was found. Apart from an overall higher hardness, adding La alone (as in Mg10Gd1La) does not show any significant effect on increasing the hardness during T6 (peak aged condition after $4 \mathrm{~h}$ ). Adding Nd on the other hand shows a remarkable increase in hardness during T6 in Mg10Gd1Nd and Mg10Gd1Nd1La, peak aged condition is reached after $12 \mathrm{~h}$ for Mg10Gd1Nd and after 10h for Mg10Gd1Nd1La. 


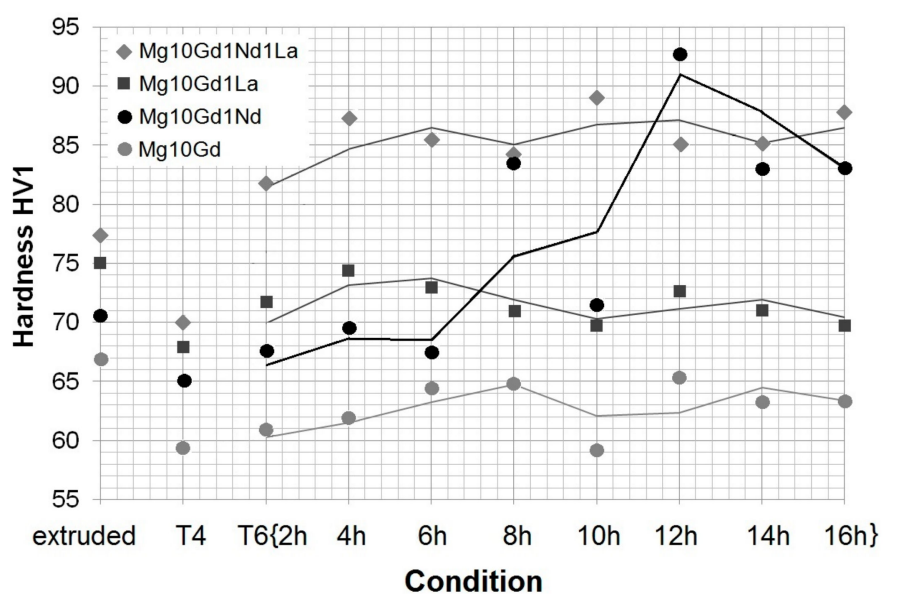

Figure 5. Effect of adding $\mathrm{Nd}$ or/and La on hardness during precipitation hardening.

Figure 6a shows the bending stress-outer strain curves of extruded $\mathrm{Mg} 10 \mathrm{Gd} x \mathrm{Nd} x \mathrm{La}$ in the 3-point bending tests [5]. The binary alloy Mg10Gd shows the highest outer strain before fracture. Alloying reduces outer strain, especially when La is added. Brittle and coarse secondary phases containing La causes micro cracks, even before the main crack initiates, see Figure $7 \mathrm{~b}$. Unexpectedly, T6 could not improve fracture toughness (Figure $6 \mathrm{~b}$ ), mostly because of the strong grain growth and low solubility of $\mathrm{La}$ in $\mathrm{Mg}$, which does not refine the secondary phases. Due to the strong grain growth in $\mathrm{Mg} 10 \mathrm{Gd}$, the ductility was significantly reduced. However, apart from Mg10Gd, all alloys showed an increased yield strength, especially the alloys containing Nd. Overall, there is no improvement in toughness by precipitation heat treatment, mainly because of the much lower ductility. Mg10Gd1Nd loses ductility the greatest-here, many hydrides are found in the fracture surface.

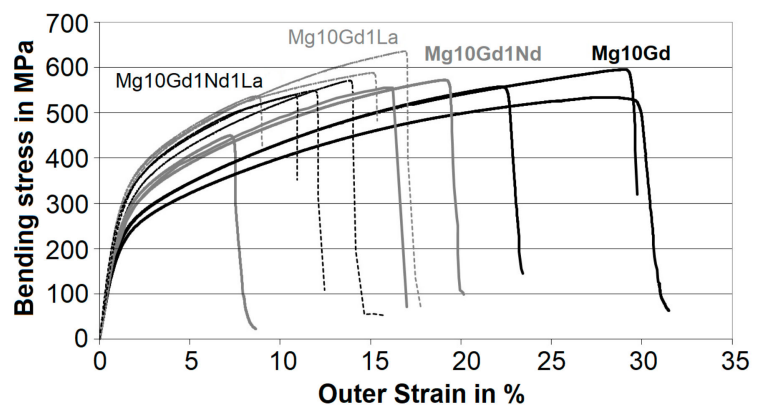

(a)

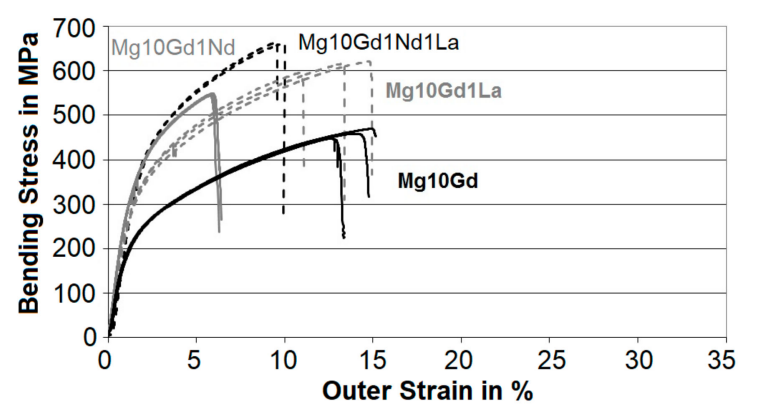

(b)

Figure 6. Influence of precipitation hardening on bending of $\operatorname{Mg} 10 \mathrm{Gd} x \mathrm{Nd} x \mathrm{La}$ : bending stress-outer strain curves of (a) extruded and (b) T6-12 h.

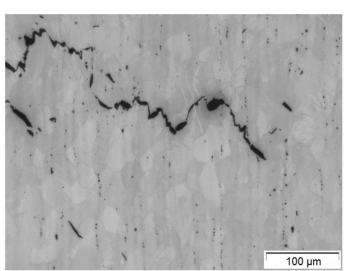

(a)

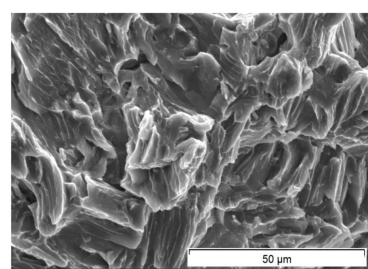

(b)

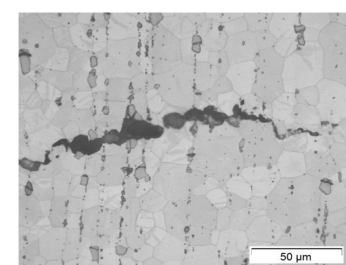

(c)

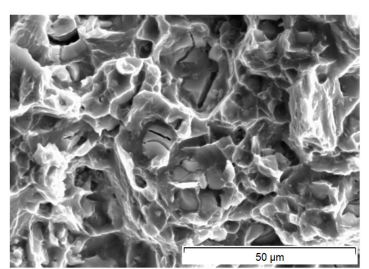

(d)

Figure 7. Micrographs at the crack tip $(\mathbf{a}, \mathbf{c})$ and SEM images of the fracture surface $(\mathbf{b}, \mathbf{d})$ of crack propagation under bending in $(\mathbf{a}, \mathbf{b})$ extruded Mg10Gd and (c,d) extruded Mg10Gd1Nd1La. 
Crack propagation under 3-point bending, in extruded Mg10Gd and Mg10Gd1Nd, is mostly driven by micro-cracks at the twin boundary (see micro-cracks in the area around the crack tip in Mg10Gd in Figure 7a and also the images in Reference [5]). The crack-tip stress field causes micro cracks at twin boundaries nearby. The alloys with La showed a suppressed twinning, but crack initiation and propagation was caused by brittle and coarse precipitates (see area around the crack tip in Mg10Gd1Nd1La in Figure 7c). The brittle and coarse precipitates fracture (micro cracking) in the plastic deformation zone in front of the crack tip and redirect the crack propagation according to the crack-tip stress field. Comparing Figure 7d-b, the fracture surface of Mg10Gd1Nd1La shows a high amount of micro cracks along the main crack. The SEM image of Mg10Gd (Figure 7b) displays the presence of dimples, which are indicative of ductile failure, and a small fraction of cleavage steps. The micrograph of extruded Mg10Gd1Nd1La (Figure 7c) shows a rather straight line in crack growth, the fraction of cleavage steps has almost disappeared.

Since the brittle and coarse secondary phases, in the La containing alloys, play an important (negative) role in crack initiation, 3-point bending tests were carried out up to a certain outer strain value that did not cause the main crack to initiate (outer strain values of $8 \%, 10 \%$, and $12 \%$ were chosen). The aim was to check whether there are micro cracks prior to the main crack. The micrographs in Figure 8 show representative images of the areas of the highest tension and compression of the alloy Mg10Gd1Nd1La. Figure 8a shows a surface area at the tension side of a sample strained to $8 \%$. It can be seen that the large particles are cracked (bottom left) and would initiate the crack in the matrix material by further loading.

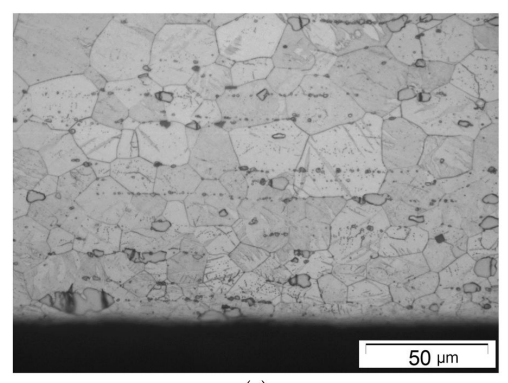

(a)

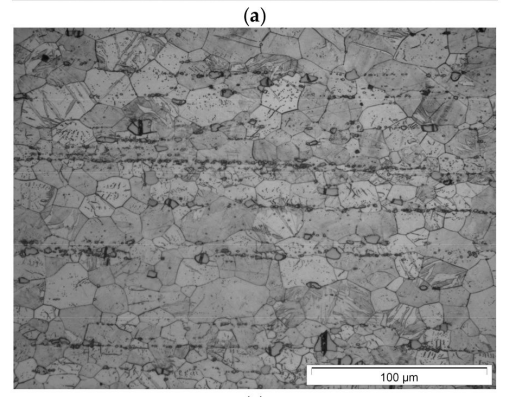

(c)

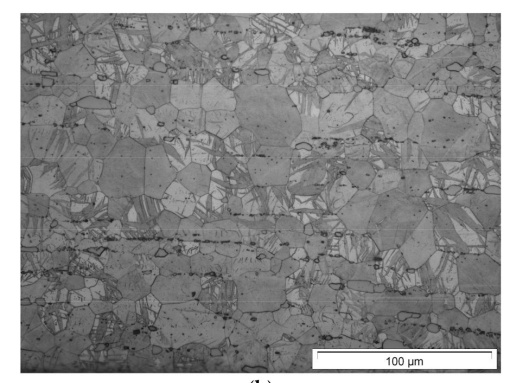

(b)

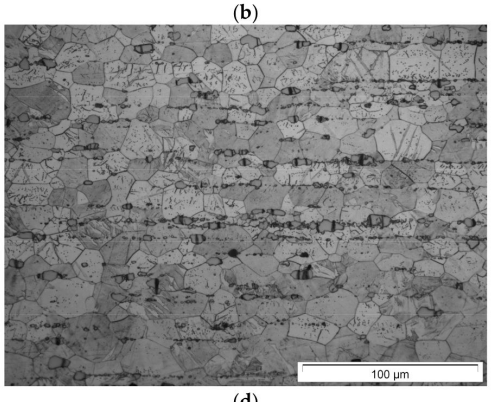

(d)

Figure 8. Crack initiation at brittle secondary particles in extruded Mg10Gd1Nd1La: (a) tension side at $8 \%$ outer strain; (b) compression side at $10 \%$ outer strain; (c) tension side at $10 \%$ outer strain; and (d) tension side at $12 \%$ outer strain.

At this stage there are not many twinned grains at the tension side. The micrograph in Figure $8 \mathrm{~b}$ shows the compression side at $10 \%$ strain and reveals many twinned grains. The particles, on the other hand, are not cracked. That indicated that they are only acting in a brittle manner when tensile loading is applied. Figure $8 c, d$ show micrographs at the tension side at 10 and $12 \%$ strain. The amount of cracked particles has increased. It can be seen that the larger particles crack first. Strain twinning is also found, mainly in the coarser grains. Taking these images together explains the reduction in ductility by alloying La; the main crack gets "guided" by cracked particles, giving a path of less resistance to crack propagation. 


\subsection{Heat Treatment and Crack Propagation}

As seen in the bending stress-outer strain curves in Figure 5, precipitation hardening (T6) could not improve fracture toughness. The toughness even gets worse during T6, which is mostly based on the strong grain growth and low solubility of $\mathrm{La}$ in $\mathrm{Mg}$. The mechanism of crack initiation and propagation is the same as in the extruded condition; in the binary alloy Mg10Gd, the crack follows twinned boundaries (Figure 9a), and in the alloys containing La, the crack propagates along the stress fields of cracked large particles (Figure 9b). The strong grain growth does not help the situation, less grain boundaries act as barriers and direction changes occur during crack propagation. The undissolved La-containing particles will grow, which increases the ability to crack strongly.

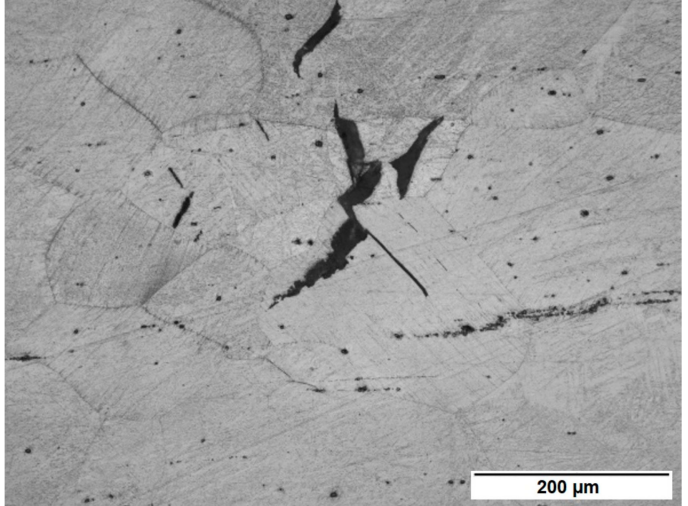

(a)

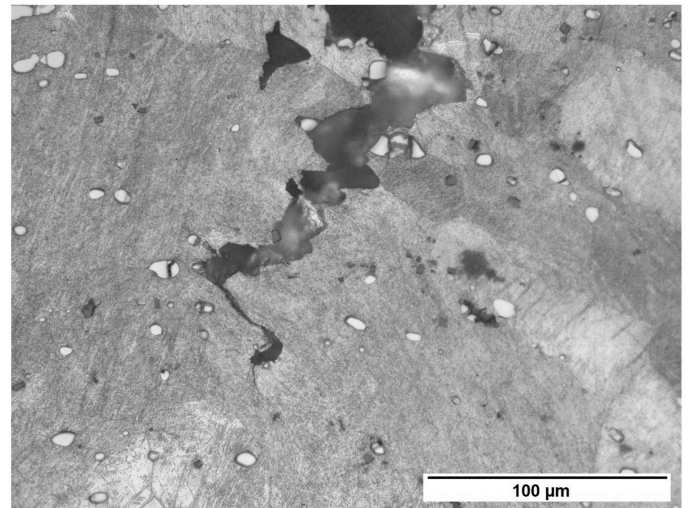

(b)

Figure 9. Micrographs of crack propagation (crack tip) under bending in precipitation hardened alloys: (a) Mg10Gd and (b) Mg10Gd1Nd1La.

\subsection{Heat Treatment and Corrosion}

Figure 10 shows the optical morphology of the samples after corrosion-by immersion and treatment with chromic acid. A difference among the alloys, as well as the material condition, can be clearly seen. Mg10Gd, independent of the heat treatment condition and all alloys in T6 condition, do show some local corrosion, but an almost all-over passive corrosion layer is formed. The film developed is either grey-white in color or appears black. Adding Nd and/or La to Mg10Gd causes a significant proportion of material damage; corrosion of the extruded condition appears all-over and the T4 condition samples still show initial surface areas on the side surface. The corrosion rate, by the immersion of the alloys in T6 condition, is below $0.5 \mathrm{~mm} /$ year. Extruded and T4 conditions show very high corrosion rates.

Looking at the extruded condition first, alloying $\mathrm{Nd}$ to $\mathrm{Mg} 10 \mathrm{Gd}$ increases the corrosion rate from $2.1 \mathrm{~mm} /$ year to $17.0 \mathrm{~mm} /$ year. Alloying La causes a corrosion rate of $36.8 \mathrm{~mm} /$ year and alloying $\mathrm{Nd}$ and La brings the corrosion rate slightly down to $30 \mathrm{~mm} /$ year. However, these high corrosion rates are not acceptable, and because of the finer grain size, compared to T4 and T6, this was not expected. Even if it was assumed that La was a substitute for $\mathrm{Nd}$ that would improve the corrosion resistance, no protective layer could have formed in static immersion in order to cause the highest corrosion rates from this series. Even the grain growth was significant during solution heat treatment; T4 brings the corrosion rates for the ternary and quaternary alloys down to $8.9 \mathrm{~mm} /$ year for Mg10Gd1Nd, $11.3 \mathrm{~mm} /$ year for Mg10Gd1La, and $22.6 \mathrm{~mm} /$ year for Mg10Gd1Nd1La. Only the binary alloy Mg10Gd shows a slight increase in corrosion rate by T4, from 2.1 to $3.5 \mathrm{~mm}$ /year, and here the grain growth was most pronounced (up to $140 \mu \mathrm{m}$ ). The role of the grain size is not completely clear yet, but often grain refinement acts positively on the corrosion rate $[17,18]$. However, in this study, other factors might have played a role. Solution heat treatment may have relieved internal stresses from extrusion and large $\mathrm{Mg}_{5} \mathrm{Gd}$ particles, which are not at their best distribution, will have dissolved. Precipitation 
hardening seems to be the favorite heat treatment condition T6 for this alloy series; the grain size does not change significantly, compared to $\mathrm{T} 4$, and the formation of finer dispersed $\mathrm{Mg}_{5} \mathrm{X}$ particles containing $\mathrm{Gd}$ and $\mathrm{Nd}$, which only cause an increase in hardness when containing $\mathrm{Nd}$, improves the corrosion resistance greatly, compared to the solution heat treated condition. It appears that the relationship between finer and coarser particles, as well as solute elements in the matrix in the aged condition, form a protective oxide layer which brings the corrosion rate down to less than $0.5 \mathrm{~mm} /$ year.

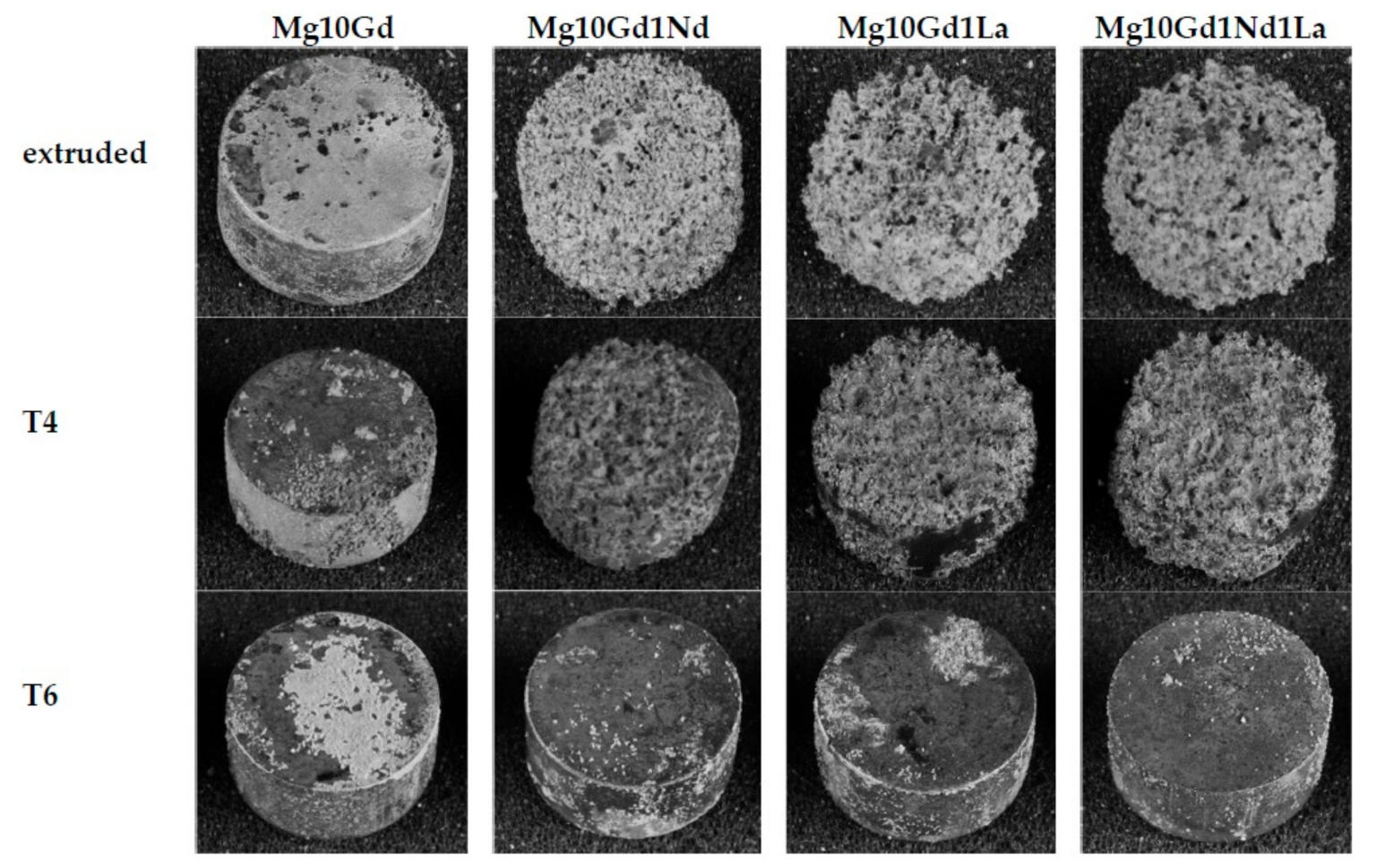

Figure 10. Optical morphology of samples corroded by immersion: the top row shows the extruded condition, the middle row shows T4, and the bottom row shows T6 (initial diameter $10 \mathrm{~mm}$ ).

Just as important as the corrosion rate is the corrosion morphology. In this study, cross-sectional macro and micrographs have been used to evaluate the pit shape, depth, and width. Pits are caused under additional mechanical load stress peaks and are dangerous when they are deeper than they are wide. When corrosion pits under ongoing corrosion overlap, they form wide and shallow pits. Their notch effect is much smaller than in deep corrosion pits. Figure 11a shows a representative cross-section of $\mathrm{Mg} 10 \mathrm{Gd} 1 \mathrm{Nd}$ in $\mathrm{T} 6$ condition after immersion testing-there is no corrosion attack at all. The pitting factor in this case is one (deepest pit divided by average corrosion taken from the corrosion rate). Mg10Gd1Nd seems to form an overall protecting and passive layer.

In Figure 11b,c the cross-section macrographs of Mg10Gd1La after immersion in extruded and T6 conditions are shown. Figure $11 \mathrm{~b}$ represents all cross-sections investigated in the ternary and quaternary alloys in extruded and T4 conditions. The pitting factor start from to up to 6.2, see Table 3. There is a strong correlation between the corrosion rate and the pitting factor. When the corrosion rate is high (alloying with $\mathrm{Nd}$ and/or La in extruded and T4 condition), the pitting factor is in a medium range. There are pits, but since they overlap during ongoing corrosion, they are not as deep. Adding La increases the corrosion rate significantly and brings the pitting factor down to 2.1 in the extruded condition, and to 3.7 in the T4 condition. From Table 3, it can be seen that for Mg10Gd, the pitting factors are the highest due to having a low corrosion rate and an incomplete dense passive layer. The T4 condition shows the smallest value, while the corrosion rate is the highest. As mentioned before, precipitation hardening results in a very low corrosion rate, but apart from Mg10Gd1Nd, the passive layer is non-uniform and deep pits develop (see Figure 11c for Mg10Gd1La), causing low pitting 
resistivity with pitting factors at a very high level. The notch effect under a mechanical load would be unacceptable.

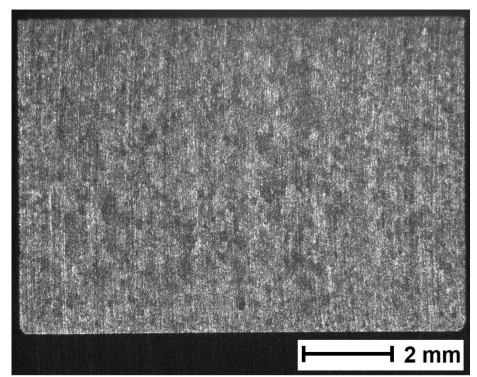

(a)

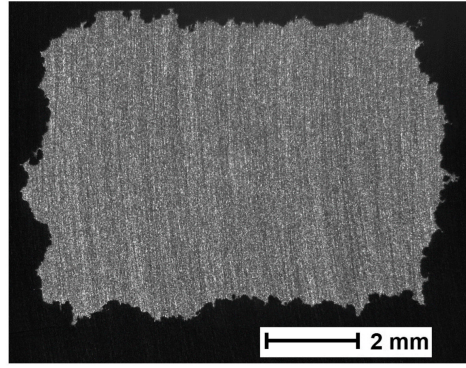

(b)

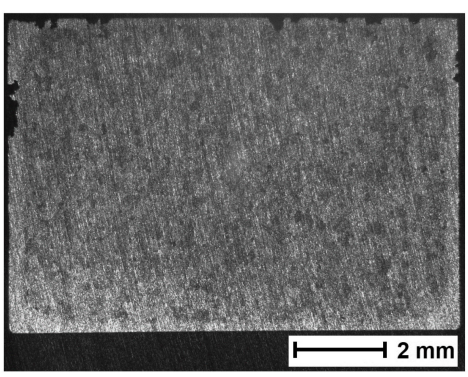

(c)

Figure 11. Cross-section macrograph of the samples after corrosion by immersion: (a) Mg10Gd1Nd in T6 condition showing no corrosion attack; (b) Mg10Gd1La in extruded condition corroded all-over; and (c) Mg10Gd1La in T6 condition corroded locally.

Table 3. Corrosion by immersion: Pitting factor.

\begin{tabular}{ccccc}
\hline Alloy Condition & Mg10Gd & Mg10Gd1Nd & Mg10Gd1La & Mg10Gd1Nd1La \\
\hline extruded & 15.1 & 3.5 & 2.0 & 2.1 \\
T4 & 13.8 & 6.2 & 6.1 & 3.7 \\
T6 & 88.8 & 1.0 & 75.0 & 82.9 \\
\hline
\end{tabular}

Figure 12 shows the current density-potential curves from the polarization tests of $\mathrm{Mg} 10 \mathrm{Gd} 1 \mathrm{Nd}$ in different heat treatment conditions in Figure 12a and in T6 conditions of all alloys in Figure 12b.

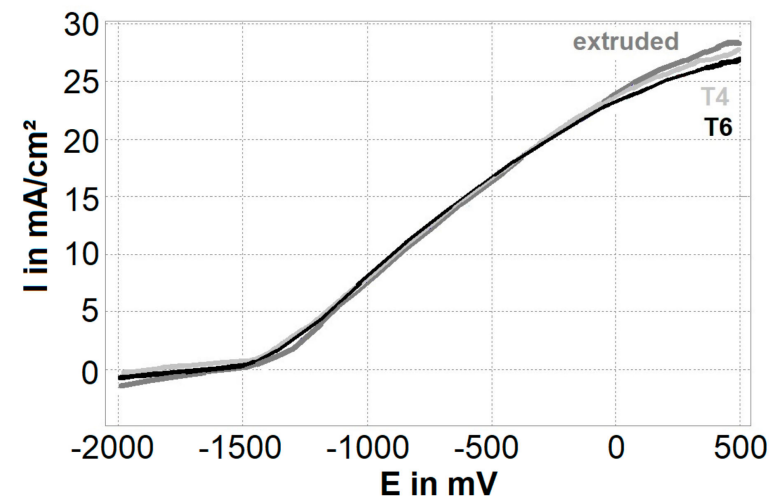

(a)

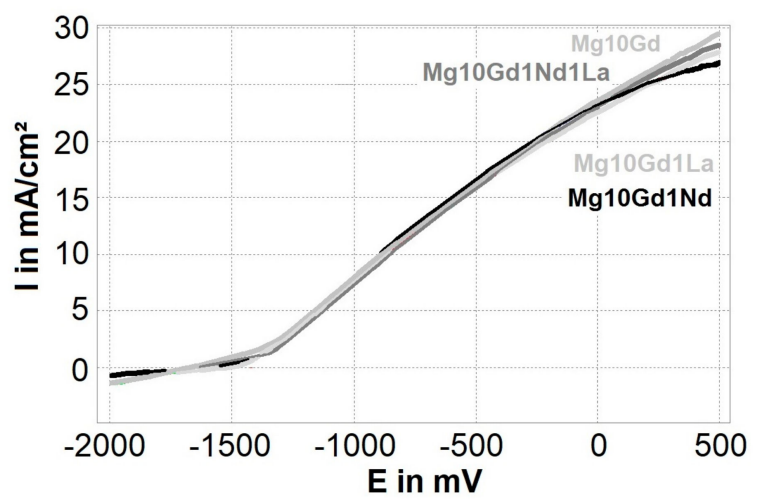

(b)

Figure 12. Current density-potential curves from polarization tests of Mg10Gd1Nd in different heat treatment condition (a) and in the T6 condition of all alloys (b).

The characteristics of anodic corrosion (Figure 12a) do not differ much in Mg10Gd in regards to its dependence on the heat treatment condition. Around $250 \mathrm{mV}$, a slight passivation can be seen, and is most pronounced for T6. The corrosion behavior of the T6 condition of all alloys (Figure 12b) does not differ much either. However, the binary alloy Mg10Gd does not show any hint of passivation-on the other hand, Mg10Gd1Nd shows the most.

Figure 13 compares the corrosion rate of the immersion tests (Figure 13a, the values have been discussed already) and the cross-sectional corroded area of the polarization tests (Figure 13b), which is used here to correlate to the corrosion rate. The difference in corrosion behavior is much smaller in polarization. The La-containing alloys show the largest differences in corrosion rate in immersion tests, 
but the smallest in polarization. The corrosion rate values, by the immersion of Mg10Gd in different heat treatment conditions, are very close, but scatter the most in polarization. This means that there is a strong dependence on the methodology of the corrosion test; in immersion tests the progress of corrosion damage is here obtained from the immersion length. Since there is no electrochemical load applied, the sample will behave as it would in an open circuit potential measurement and finds its equilibrium. The corrosion layer formed does not need to withstand increasing potential difference. Since, in polarization tests, the potential increases, anodic corrosion is forced, resulting in ongoing anodic corrosion, pseudo passivation, or passivation. The passive layer might break down.

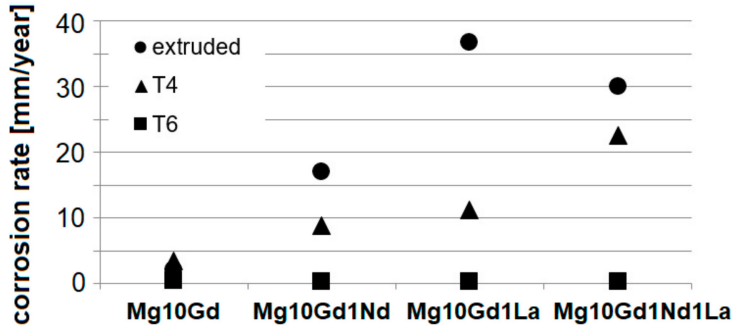

(a)

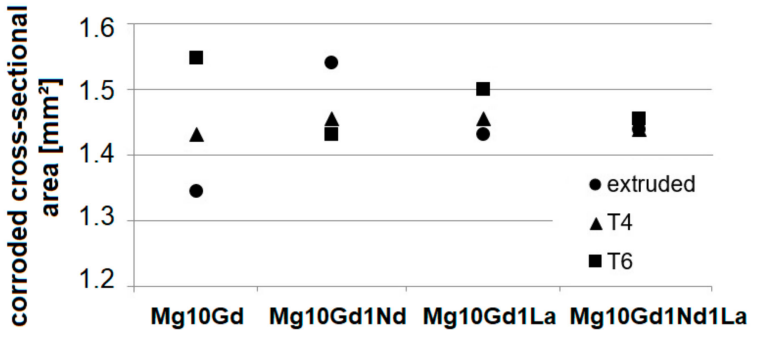

(b)

Figure 13. Corrosion rate and corroded area influenced by alloy and material condition: (a) corrosion rate by immersion, and (b) corroded area by polarization.

The current density-potential curves shown, and their current density value at a potential of $500 \mathrm{mV}$, underlines the corrosion ability. In Figure 12a, it can be seen that the current density value of the extruded Mg10Gd1Nd at $500 \mathrm{mV}$ is the highest, agreeing with the highest corroded cross-sectional area in the diagram in Figure 13b. T6 shows the lowest value of corroded area, agreeing with the lowest current density value. Similar agreement is found between the current density value at $500 \mathrm{mV}$ and the corroded cross-sectional areas in the T6 condition in all alloys (Figure 12b). The highest current density value $\left(\sim 30 \mathrm{~mA} / \mathrm{cm}^{2}\right)$ for $\mathrm{Mg} 10 \mathrm{Gd}$ agrees with the highest corroded area of $1.55 \mathrm{~mm}^{2}$ in the cross-section macrograph (see Figure 13b), Mg10Gd1Nd shows, for both data sets, the lowest value. However, other than in immersion, there seems to be no trend in polarization tests among the alloys and heat treatment conditions. Mg10Gd1Nd1La seems to act independent of the heat treatment condition in polarization tests.

The pitting factors with values around two are much smaller in polarization than in immersion (see Table 4, evaluated from cross-sectional macrographs in Figure 14). Due to ongoing anodic corrosion in polarization, pits start to overlap and form a more uniform corrosion morphology. The deepest pits are found around $356 \mu \mathrm{m}$ in Mg10Gd1Nd (Figure 14a), but due to a high average corrosion depth, it also causes a pitting factor of only two. Since the corrosion pits in polarization are often wide and shallow, they would not be very dangerous when exposed to an additional load. Pits in immersion samples reach depths up to $1000 \mu \mathrm{m}$. The correlation between the corrosion rate and the pitting factor is not seen in the polarization tests.

Table 4. Corrosion by polarization: deepest pit in $\mathrm{mm} /$ pitting factor.

\begin{tabular}{ccccc}
\hline Alloy Condition & Mg10Gd & Mg10Gd1Nd & Mg10Gd1La & Mg10Gd1Nd1La \\
\hline extruded & $0.28 / 2.2$ & $0.36 / 2.1$ & $0.33 / 1.9$ & $0.27 / 1.9$ \\
T4 & $0.30 / 2.0$ & $0.29 / 2.1$ & $0.31 / 1.9$ & $0.24 / 1.6$ \\
T6 & $0.34 / 2.0$ & $0.27 / 1.8$ & $0.32 / 2.0$ & $0.29 / 1.8$ \\
\hline
\end{tabular}




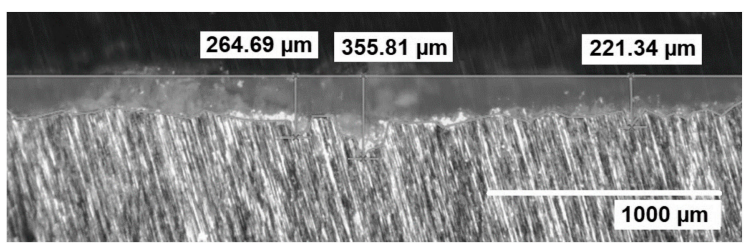

(a)

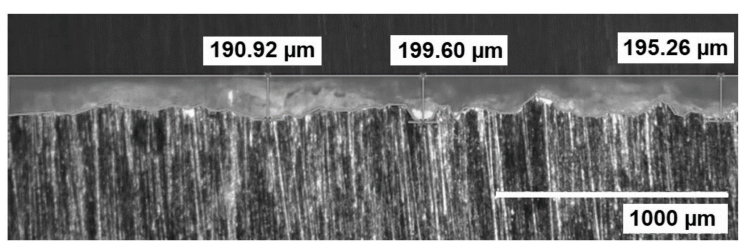

(b)

Figure 14. Cross-section macrograph of the samples after corrosion by polarization of Mg10Gd1Nd: (a) in extruded condition and (b) in T6.

By taking the better mechanical properties of the extruded alloys Mg10Gd and Mg10Gd1Nd into account, where Mg10Gd1Nd even shows a higher bending yield strength, it can be stated that adding $\mathrm{Nd}$ increases the corrosion rate in both immersion $(\times 8)$ and polarization $(\times 1.15)$. This increase brings the pitting factor down, even more so in immersion from 15.1 to 3.5, compared to polarization from 2.2 to 2.1. Finally, by adding $\mathrm{Nd}$ and / or La, as well as applying different heat treatments, the mechanical and corrosion properties can be tailored. It is difficult to say which is the best condition among the alloys. It is certain however, that precipitation hardening did not improve the toughness, but did improve the corrosion rate. Mg10Gd1Nd has the highest resistivity to pitting corrosion.

\section{Conclusions}

The influence of precipitation hardening on the mechanical and corrosion properties of Mg10Gd alloyed with $\mathrm{Nd}$ and/or La were studied. The following conclusions can be made:

- $\mathrm{Nd}$ and/or La increases tensile and bending yield strength significantly, but due to brittle secondary phases, it hardly improves the maximum strength.

- The volume fraction and particle size of secondary phases increase with increasing alloying elements.

- Alloys containing La appear less ductile.

- Crack propagation in binary Mg10Gd is mostly driven by twinning.

- The increased amount and size of secondary phases by the addition of $\mathrm{Nd}$ and/or La seems to suppress twinning, but on the other hand, the crack initiation and propagation is caused by these brittle and coarse secondary phases-so precipitation hardening could not improve fracture toughness.

- Heat treatment causes strong grain growth —with the addition of alloying elements, the grain size stays smaller, in alloys with $\mathrm{Nd}$ precipitation hardening occurs-but at the expense of ductility. Particles still act in a brittle manner and influence crack growth.

- Even though the extruded material shows the smallest grain size, the corrosion rates in immersion show (apart from Mg10Gd) the highest values, due to the coarse precipitates and especially when alloyed with La.

- T6 shows the lowest corrosion rate in immersion, but very high pitting factors, apart from Mg10Gd1Nd, where the overall highest pitting resistivity is found. A pitting factor of one indicates a dense uniform corrosion layer.

- A strong correlation between the corrosion rate and the pitting factor occurs in immersion tests. When the corrosion rate is high, the pitting factor is decreased.

- There seems to be no trend in polarization tests among the alloys and the heat treatment condition.

- Corrosion morphology in polarization is more uniform where pitting factors around two are found.

- La is not a useful substitute for Nd regarding mechanical properties and corrosion behavior. 
Author Contributions: P.M., C.M. and N.H. conceived and designed the experiments; C.M. and M.B. performed experiments; P.M. and C.M. analyzed the data; P.M., C.M. and N.H. wrote the paper.

Funding: The research leading to these results has received funding from the Helmholtz Virtual Institute "In vivo studies of biodegradable magnesium based implant materials (MetBioMat)" under grant agreement VH-VI-523.

Acknowledgments: The authors thank Sören Müller (Extrusion Research and Development Center TU Berlin) for extrusion, Hartmut Habeck (UASS) and Marius-Antonel Budau (Alecsandri University of Bacau, Romania) for supporting corrosion tests.

Conflicts of Interest: The authors declare no conflict of interest. The founding sponsors had no role in the design of the study; in the collection, analyses, or interpretation of data; in the writing of the manuscript, and in the decision to publish the results.

\section{References}

1. Rokhlin, L.L. Magnesium Alloys Containing Rare Earth Elements—Structure and Properties; Taylor \& Francis: London, UK, 2003; ISBN 9780415284141.

2. Hort, N.; Huang, Y.; Fechner, D.; Störmer, M.; Blawert, C.; Witte, F.; Vogt, C.; Drücker, H.; Willumeit, R.; Kainer, K.U.; et al. Magnesium alloys as implant materials-Principles of property design for Mg-RE alloys. Acta Biomater. 2010, 6, 1714-1725. [CrossRef] [PubMed]

3. Mirza, F.A.; Chen, D.L. Fatigue of rare-earth containing magnesium alloys: A review. Fatigue Fract. Eng. Mater. Struct. 2014, 37, 831-853. [CrossRef]

4. Maier, P.; Mendis, C.L.; Wolff, M.; Hort, N. Crack Propagation under Bending in Cast Mg10-GdxNd-T4 Alloys. In Magnesium Technology 2014; The Minerals, Metals \& Materials Society Series; Alderman, M., Manuel, M.V., Hort, N., Neelameggham, N.R., Eds.; Springer: Cham, Switzerland, 2014; pp. 77-82. ISBN 978-1-118-88816-2.

5. Maier, P.; Mendis, C.L.; Wolff, M.; Hort, N. Twinning assisted crack propagation of Magnesium-Rare Earth casting and wrought alloys under bending. Mater. Sci. Forum 2015, 828-829, 311-317. [CrossRef]

6. Maier, P.; Richter, A.; Tober, G.; Hort, N. Effect of grain size and structure, solid solution elements, precipitates and twinning on nanohardness of Mg-RE alloys. Mater. Sci. Forum 2013, 765, 491-495. [CrossRef]

7. Hay, J.L.; Agee, P. Mapping the Mechanical Properties of Alloyed Magnesium (AZ 61). In Magnesium Technology 2013; The Minerals, Metals \& Materials Society Series; Hort, H., Mathaudhu, S.N., Neelameggham, N.R., Alderman, M., Eds.; Springer: Cham, Switzerland, 2013; pp. 329-332. ISBN 9781118605523.

8. Hampl, M.; Blawert, C.; Silsa Campos, M.R.; Hort, N.; Peng, Q.; Kainer, K.U.; Schmid-Fetzer, R. Thermodynamic assessment and experimental study of Mg-Gd alloys. J. Alloys Compd. 2013, 581, 166-177. [CrossRef]

9. Peng, Q.; Ning, M.; Hui, L. Gadolinium solubility and precipitate identification in Mg-Gd binary alloy. J. Rare Earths 2012, 30, 1064-1068. [CrossRef]

10. Schmid-Fetzer, R.; Gröbner, J.; Kozlov, A.; Hampl, M.; Easton, M.A.; Zhu, S.M.; Gibson, M.A.; Nie, J.F. Thermodynamics of phase formation in Mg-La-Ce-Nd alloys. In Magnesium Technology 2013; The Minerals, Metals \& Materials Society Series; Hort, H., Mathaudhu, S.N., Neelameggham, N.R., Alderman, M., Eds.; Springer: Cham, Switzerland, 2013; pp. 243-248. ISBN 9781118605523.

11. Silva, M.; Scharnagl, B.; Blawert, C.; Kainer, K.U. Improving Corrosion Resistance of Mg10Gd Alloy. Mater. Sci. Forum 2013, 765, 673-677. [CrossRef]

12. Willumeit, R.; Möhring, A.; Feyerabend, F. Optimization of Cell Adhesion on Mg Based Implant Materials by Pre-Incubation under Cell Culture Condition. Int. J. Mol. Sci. 2014, 15, 7639-7650. [CrossRef] [PubMed]

13. Ding, Y.; Wen, C.; Hodgson, P.; Li, Y. Effects of alloying elements on the corrosion behavior and biocompatibility of biodegradable magnesium alloys: A review. J. Mater. Chem. B 2014, 2, 1912-1933. [CrossRef]

14. Zhang, J.; Zhang, D.; Tian, Z.; Wang, J.; Liu, K.; Lu, H.; Tang, D.; Meng, J. Microstructures, tensile properties and corrosion behavior of die-cast Mg-4Al-based alloys containing La and/or Ce. Mater. Sci. Eng. A 2008, 489, 113-119. [CrossRef]

15. Maier, P.; Gentzsch, L.; Hort, H. Voltammetric studies of extruded pure Mg in different electrolytes and its corrosion morphology. In Magnesium Technology 2017; Solanki, K., Orlov, D., Singh, A., Neelameggham, N.R., Eds.; Springer: Cham, Switzerland, 2017; pp. 429-437. ISBN 978-3-319-52391-0. 
16. Maier, P.; Bechly, M.; Hort, H. Solution heat treatment on mechanical properties and corrosion of extruded Mg5Gd compared to pure Mg. In Proceedings of the Materials Science and Technology 2017 (MS\&T17), Pittsburgh, PA, USA, 8-12 October 2017; pp. 76-83.

17. Argade, G.R.; Panigrahia, S.K.; Mishra, R.S. Effects of grain size on the corrosion resistance of wrought magnesium alloys containing neodymium. Corros. Sci. 2012, 58, 145-151. [CrossRef]

18. Aung, N.N.; Zhou, W. Effect of grain size and twins on corrosion behaviour of AZ31B magnesium alloy. Corros. Sci. 2010, 52, 589-594. [CrossRef]

2018 by the authors. Licensee MDPI, Basel, Switzerland. This article is an open access article distributed under the terms and conditions of the Creative Commons Attribution (CC BY) license (http://creativecommons.org/licenses/by/4.0/). 